Bangladesh Journal of Bioethics 2017; 8(2): 11-18

\title{
ZIKA Virus Disease as Public Health Emergency and Ethics
}

\section{Rhyddhi Chakraborty ${ }^{1}$ and Edmond Fernandes ${ }^{2}$}

1.Researcher (Bioethics, United Kingdom) and Visiting Faculty of Philosophy and Global Health (American University of Sovereign Nations, Arizona, USA), Email: rhyddhi_414@yahoo.co.in

2. Founder and CEO, CHD Group, India and Adjunct Faculty, Dept. of Public Health, KSHEMA, Nitte University

Abstract: This paper argues that Zika virus infection has its ethical implications beyond the reproductive health of women. It claims that Zika virus infection like public health emergency exposes the underlying health determinants and health status of women. Therefore, ethical mitigation of Zika like public health emergencies should consider these underlying health determinants and health status of women. For, undermining and overlooking these underlying determinants and health status of women, during the public health emergencies, enhance the health inequities. The recent Zika virus infection in Brazil has triggered different ethics consultation and has prompted to outline ethical recommendations. However, the recommendations have either focused on the reproductive health of women or on the core strategies of public health emergency. Considering this as a gap in perspective to prepare for Zika like public health emergencies, this paper argues that it is the underlying holistic health of women, precisely, health capability, which should be given due ethical consideration. Finally, the paper concludes highlighting the fact that focusing on the holistic health of the women during Zika like public health emergencies and beyond can bring in long-term benefits for global health equity.

Key Words: Ethics, Health, Women, Zika

Introduction: One of the remarkable incidences of 2016 is the hosting of Rio Olympics in Brazil, a Latin American country which was trying to manage and control Zika virus outbreak. Gradually, as the disease continued to spread to other countries, the potential threat of this Aedes mosquito-borne disease, especially its possible association with microcephaly and other neurological disorders, has prompted World Health Organization (WHO) to declare it as public health emergency of international concern ${ }^{1}$. The incidences out of Zika virus disease in Brazil have also highlighted several novel and known ethical issues, which thereby, prompted international agencies to review ethical considerations and driven them to frame ethical guidance to prepare and act for Zika like public health emergencies ${ }^{2,3}$. Given the need of the situation in Brazil, ethics consultations have focused much more on the reproductive health of the women and on the strategic responses as any public health emergency demands. However, this paper argues, Zika virus-like diseases have the capacity to unveil the underlying health determinants, expose the existing poor health status of women, and have long-term health implications for the affected women. And, when these underlying determinants and health status of women are undermined, especially in ethics consultation, the disease mitigation strategies fall short of addressing health inequity. Consequently, the disease then contributes to and enhances health inequities ${ }^{4}$. Therefore, during Zika like outbreaks, the paper claims, the 
ethical attention, should not just be restricted to strategic responses but should also be driven towards addressing the underlying health determinants and health conditions.

The Seen and Unforeseen Impacts of Zika Virus Disease: Zika virus disease is an Aedes mosquitoes borne infection. Symptoms, usually, include mild fever, skin rash, conjunctivitis, muscle and joint pain, malaise, or headache, normally lasting for 2-7 days ${ }^{5}$. Since its first appearance in 1947 in the Uganda, Zika virus disease surprised the world by its re-emergence in 2015. Unlike its previous occurrences, the recent Zika virus infection came to be known as the first of its kind associated with human birth defects. It was found to be evidently cooccurring with neurological complications such as Guillain-Barre Syndrome and microcephaly, for which there are no vaccines available ${ }^{6}$. In between 22 October 2015 and 16 April 2016, Brazil reported a total of 7150 suspected cases of microcephaly and/or central nervous system malformations. Of these 1168 were suggestive of congenital infection and 246 child deaths occurred after birth or during pregnancy ${ }^{7}$ Children born with Zika congenital complications may reveal no symptoms at birth but later could develop epilepsy, convulsions, cerebral palsy, physical and learning disabilities, hearing loss, vision problems at different stages of their growth and development ${ }^{8}$. The rising incidences of the association of microcephaly and Zika virus disease provoked Brazil to declare Zika outbreak as a national public health emergency on 11 November $2015^{9}$. From February 2016 onwards, Zika crossed the Brazilian border and was found in places such as Venezuela where already there were existing menaces of Aedes mosquito ${ }^{10}$. In February 2016, considering the severity of the situations in Brazil and other Latin American countries, World Health Organization (WHO) declared Zika virus disease as a public health emergency of international concern (PHEIC) ${ }^{11}$.

Despite being mosquito-borne, Zika virus infection gradually turned out to transmit person-toperson infection through the flow of the amniotic fluids of pregnant mothers to the child, the body fluids during sexual intercourse, blood transfusion, and laboratory and health-care setting exposure $^{12}$. However, it is the mother to child infection that gained momentum, caused most of the transmissions recently, and incurred a huge loss to Latin American countries. The World Bank (WB) estimated $\$ 3.5$ billion economic loss out of 2016 Zika-related effects in Latin America alone ${ }^{13}$.

Besides its serious medical complications and economic loss, this recent incidence of Zika virus infection had its debilitating impacts on the certain section of women and on their born and unborn children. In Brazil especially, as it has been highlighted, thousands of women of child bearing age, who have already contracted or have the plausibility to contract Zika, live particularly in Northeast part of Brazil, the region which has already the heaviest share of the burden of poverty, poor infrastructure, lack of access to health services, and high penetration of Aedes Aegypti. As became noticeable, the women of the region are living with precarious sanitation and housing, irregular water supply, poor water storage system increasing mosquito breeding and contributing to the spread of Zika and frequent outbreaks of dengue, chikungunya ${ }^{14,15}$. Given this precarious condition, when women of the region were particularly affected by Zika, A.E.Yamin, a pioneer in Global Health and Human Rights, rightly reminds that in these Zika affected region, it is the "women who have experienced their poverty and 
marginalization through their contact with indifferent health systems. It is women who again will pay the greatest consequences of the impacts of the lack of public health measures, inadequate social protection, and discriminatory laws and... may be blamed for getting

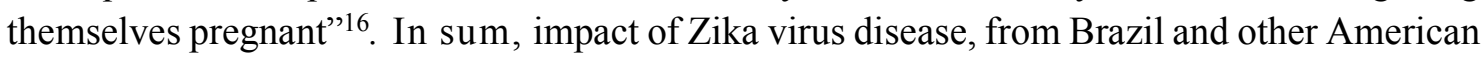
countries, brings to notice that given the underlying conditions of health in the regions, given the situation of the places being less enabled and less interactive, Zika like public health emergencies, became opportunistic to affect these women, thereby, compromising their life and health expectations.

Apart from the grave impacts on life and health expectations, the zika virus disease had its devastating impacts on reproductive health and opportunities of some women who continued to live in the Zika affected regions. Soon after the Zika outbreak, alarming calls by national governments were made to plead women to avoid and delay pregnancy. Consequently, voices were raised about the impairment of women's reproductive rights, access to safe abortion services ${ }^{1718}$. Following this line of thought and showing a concern for the right of women, the United Nations High Commissioner for Human Rights released a statement criticizing advice to delay pregnancies and affirming that "laws and policies that restrict access to sexual and reproductive health services in contravention of international standards, must be repealed and concrete steps must be taken so that women have the information, support and services they require to exercise their rights to determine whether and when they become pregnant"19. Although the UN report stands against the local or national governmental injunctions, Zika Virus disease, however, once again unleashed the fact that it is not just the impoverished who are disproportionately disadvantaged in the face of public health disasters but Zika like public health emergencies can also push the rights and choices of the women at stake and in this case, it has been the reproductive rights of some groups of women which were compromised

Realizing the interdependence of health and human rights amidst Zika outbreak, in early April 2016, the Pan American Health Organization (PAHO) issued a guidance document on the key ethical issues raised by the epidemic that echo the demand of respecting women's rights to reproduce and include the duty of all governments to provide adequate information, respect the right to choose, and provide access to comprehensive reproductive health care, social support to women and children affected by $\mathrm{Zika}^{20}$. PAHO specified that the governmental allowances to these women should include allowing each woman to know how to assess whether she wants to continue the pregnancy and whether she is willing to bear a child with the risk of this syndrome, or whether she cannot submit to it, rather than being authoritative to sacrifice the reproductive choices ${ }^{21}$. Even though the PAHO guidance mentions about respecting the rights of the women, the drastic injunctions and governance principles have provoked some groups of women to comply with the governmental system and response to Zika virus disease at the midst of the emergency period. Consequently, the sudden reactions and preparedness have compromised these women's life circumstances, and have shaken their abilities and confidences to continue the reproductive choices further in their lives. 
With the severity of the Zika, in some places of Brazil and other countries, the government had put injunctions to pregnant women to abort the unborn child. With such injunction, the fear of unsafe abortions unleashed in the Zika affected regions and unfolded different facts about unsafe abortion and its ill- consequences on the health of the women. For instance, according to a 2015 Guttmacher Institute brief, as many as $67 \%$ of poor women in Guatemala and Mexico, as compared to $38 \%$ of well-off women, who have an abortion, experienced health complications leading to the requirement of the medical treatments afterwards ${ }^{22}$. Françoise Girard, president of the International Women's Health Coalition, in the context of injunctions of Zika related abortions, raised the point that rather than implementing the authoritative injunctions to Zika related abortions in Brazil and other Latin American countries, government could have focused on the fact of improving women's health and human development by ensuring their reproductive rights, providing affordable reproductive health services (including contraception and safe abortions) and making comprehensive sexual education available to both girls and boys. As he emphasized, there is a need to assure reproductive rights in so-called normal times because next crisis cannot be predicted in advance ${ }^{23}$. The focus on improving the system and infrastructure for ensuring reproductive rights of women during normal times is reasonable. For, as some researchers pointed, failure of states to implement unrestricted abortion laws violates international human rights treaties, national constitutions protecting the right to health, privacy, human dignity, family planning, gender equality, lives free from discrimination, violence, physical and mental integrity, and free from torture, cruel, inhuman, or degrading treatment or punishment ${ }^{24}$. This paper supports Mr. Girard's and others' views on focusing on the improvement of the infrastructure of abortion and reproductive health during normal times. For, the paper claims that making ad hoc injunctions of abortions during emergency times, without securing the abortion measures in the concerned society, result in compelling the affected women to compromise their human health securities during the Zika virus disease like public health emergencies.

With the gaining momentum of Zika virus disease, gradually it became noticeable that poor pregnant women being exposed to the Zika virus were further discovering themselves to be impoverished with the potential burden of born or unborn Zika affected child. For, being a mother of a neurologically disabled child meant they could not work. Many pregnant mothers, therefore, conformed to the existing abortion infrastructure. For, they could not bear the fear, anxiety, and stress of having the responsibility of a baby with special needs, as this would place a huge burden on her poor family ${ }^{25}$. Zika affected children, on one hand, while have their unfair burden of disabled childhood, the women, on the other hand, faced the unfair burden of life circumstances, uncertainty to achieve the lives they want to value.

These foreseen and unforeseen impacts of Zika virus disease on babies, unborn children, and on women, especially in Brazil, have triggered different ethics consultation and have prompted outlining ethical recommendations. However, the recommendations have either focused on the reproductive health of women or on the ethics of Zika as a public health emergency, overlooking the need to focus on the health, both physical and mental, of the deprived women. 
The Ethical Challenges and Guidance for Zika: The proliferation of cases of congenital neurological complications of children in Brazil raised the challenge to ensure women's reproductive rights, including the rights to be pregnant and the right to interrupt the pregnancy. Therefore, PAHO came up with Zika ethics guidance highlighting the moral duty to give women of childbearing age up-to-date information, the capacity to choose between all relevant reproductive options, access to comprehensive reproductive health care, and social support. Supporting this view and categorizing the Zika affected women as the first generation and second generation affected persons, some researcher such as Diniz argue for strengthened social protection and policies for women and families with affected children, including immediate cash transfer benefits. She emphasized that women, being the main victims of this epidemic, need good science and good social policies to ensure their abilities, basic health needs, and rights as women ${ }^{26}$. For, women are more than a mother; her health comprises more than her reproductive health; she is a human, a person by herself who has a life of her own ${ }^{27}$.

With the rising cases of Zika virus disease, an international panel on Zika consultation analysed the gaps in the countries' health system and recommended increasing public health actions to reduce the risk of the effects of Zika virus infection in pregnancy, provide appropriate care and support (for women who have been exposed); reduce exposure to Zika virus infection for all people; provide appropriate clinical care and rehabilitation and continuing care for all those with long-term neurological conditions such as acute clinical services and rehabilitation; enhanced surveillance and research into diagnostics, vaccines, treatments and vector control ${ }^{28}$. In addition to the focus on these infrastructural developments, Nuffield Council proposes some general and specific ethical considerations. It focuses on ethics of data sharing, public engagement, and communication, mosquito control techniques, and maintaining a proportionate response. In short, this recent public health emergency of Zika virus prompted international agencies to delve into and discuss some old challenges for governments in controlling vectors, and dealing with issues of reliability, accessibility, diagnosis, vaccine production, and intensification of basic sanitation policies. However, these consultations overlooked the fact to reflect on why Zika like public health emergencies unleashed the old ethical issues of public health emergency preparedness and what have triggered the new issues to arise? Thinking along this line of thought, Saenz points out that 'discussion should continue on the reasons why the lessons that could have been learned are still posing challenges, and how to ensure that the same situation does not occur in a future outbreak.' And she suggests it is where there is a need of reinvigoration of the commitment to integrate ethics in health care ${ }^{29}$.

Ethics in healthcare could be inculcated during the emergency on an ad hoc basis and even before and post-disaster phases, that is, during the normal times. Ethical actions implemented on an ad hoc basis might not be as sustainable as the ethical actions implemented and practiced during normal times and even carried over to the emergency situations. And to be sustainable, a health-care system needs a vision, precisely a vision of health. An underlying vision of health would not only help in the sustainable ethical actions during the emergency period but could also help to perform fairly, in an open and transparent manner during the normal times. 
To point about the vision of healthcare, Luna points out that the definition of health by the World Health Organization, which includes mental health, is also to be remembered during Zika like public health emergencies ${ }^{30}$. However, given, the context of Zika like public health emergencies, this paper argues that Zika like public health emergencies need to consider about the women as affected agencies, their abilities and confidence to cope with these kind of situations, their enabling environment to ensure them of their health needs, and not the least, their underlying health performances which push them to be better-off and worst-off during the Zika like situations. And to consider these, the paper finds that health as capability could be the appropriate vision of health ${ }^{31}$. Under the paradigm of health capability, health is mainly considered as person's ability to be healthy and has a special moral importance for it signifies more than the simple physiological health. JPRuger defines it as, “... the ability of the individuals to achieve certain health functionings as well as the freedom to achieve those functionings" (2010:81) $)^{32}$. For, health when considered as a capability, would consider holistic and comprehensive health of the individuals, would consider the underlying factors of health affecting women, would consider women as health agencies, would compare and check their health performances, both physical and mental during the emergency and normal times, and would also consider the health capabilities of individuals and groups to cope with the circumstances, thereby, making an attempt to address the health inequities. Health, when considered as a capability, would focus on the capability of the individuals and groups- their abilities to cope with the environments; their abilities and confidences to navigate the situations to look for the optimum health, their health values that they want to achieve. However, this also implies a shared governance to enable and ensure the environment to the individuals and groups to navigate through. Focusing on the health capabilities, during normal and Zika like emergency situations and by acting on the ground of such vision, would also enable the national healthcare system to aim to contribute to global health equity but to address the local health inequities. In the present case, Zika affected countries, grounding on the Health Capability Paradigm, could simultaneously address the inequities at the local level and can move forward to contribute to global health equity. And during the public health emergency situations, grounding on the Health Capability Paradigm, the healthcare systems of the affected countries could ensure its citizens, in this case the women, the highest available treatment and diagnostic regimes at the local levels; could assess their capability to meet the demands, their shortfall, and can attempt to contribute to sustainable healthcare systems.

Conclusion: This paper mainly argues that Zika virus infection has its ethical implications to the health of women in general. Explaining certain seen and unforeseen impacts of Zika virus disease, especially in Brazil, the paper has analyzed the ethical situations and has attempted to point why there is a need of the ethical vision of health during Zika like public health emergency situations. Highlighting the lapses in the current Zika ethics consultations and recommendations, the paper claims that Zika like public health emergencies needs to focus on the ethical vision of health capability to act and promote sustainable healthcare during emergency times and normal period. Finally, highlighting the fact that during Zika like public health emergencies, healthcare systems should focus on the health capabilities of women, the paper concludes with the recommendation that the national healthcare systems should be 
adequately capable to add infrastructures to be sustainable and to contribute to global health equity.

Acknowledgement: The authors are grateful to the editorial team of the Bangladesh Journal of Bioethics and acknowledge their hard work behind the successful publication of the articles in the journal.

Author Declaration: Rhyddhi Chakraborty conceived the idea, conducted literature review, and developed the manuscript. Edmond Fernandes had drafted the first version of the manuscript.

\section{Conflict of Interests: None.}

\section{References}

1. World Health Organization (WHO). WHO statement on the first meeting of the International Health Regulations (2005) (IHR 2005) Emergency Committee on Zika virus and observed increase in neurological disorders and neonatal malformations. 1 February 2016. http://www.who.int/mediacentre/news/statements/2016/1st-emergency-committeezika/en/. Last Accessed 19 April 2017.

2. Nuffield Council on Bioethics. Briefing Note. Zika: ethical considerations.9 February 2016.

3. Pan American Health Organization (PAHO). Zika ethics consultation: ethics guidance on key issues raised by the outbreak. 6-7 April 2016. Washington D.C.

4. United Nations Development Programme (UNDP). A Socio-economic Impact Assessment of the Zika Virus in Latin America and the Caribbean: with a focus on Brazil, Colombia, and Suriname.2017.

5. World Health Organization (WHO). Zika Virus.2017. http://www.who.int/mediacentre/factsheets/zika/en/. Last accessed 14 April 2017.

6. World Health Organization (WHO). The History of Zika Virus. 2017. http://www.who.int/emergencies/zika-virus/history/en/. Last accessed 19 April 2017.

7. World Health Organization (WHO). Zika Virus Microcephaly and Guillan-Barre Syndrome. 2016. http://apps.who.int/iris/bitstream/10665/205505/1/zikasitrep_21Apr2016_eng.pdf. Last accessed 14 April 2017.

8. World Health Organization (WHO). Microcephaly, Media Centre.2016. http://www.who.int/mediacentre/factsheets/microcephaly/en/. Last accessed 14 April 2017.

9. World Health Organization (WHO). The History of Zika Virus.2016. http://www.who.int/emergencies/zika-virus/history/en/. Last accessed 14 April 2017.

10. Ibid.

11. World Health Organization (WHO). WHO statement on the first meeting of the International Health Regulations (2005) (IHR 2005) Emergency Committee on Zika virus and observed increase in neurological disorders and neonatal malformations. 1 February 2016. http://www.who.int/mediacentre/news/statements/2016/1st-emergency-committeezika/en/. Last Accessed 19 April 2017.

12. Centre for Disease Control and Prevention (CDC). Transmission and Risks.2017. https://www.cdc.gov/zika/transmission/index.html. Last accessed 12 April 2017. 
13. Lawrence OG and James GH Jr. Zika Virus and Global Health Security Georgetown Law Faculty Publications and Other Works. 2016: 1802. http://scholarship.law.georgetown.edu/facpub/1802.

14. Jacqueline P. Women's reproductive rights and the Zika virus epidemic. THEMATIC ISSUE: ZIKA AND PREGNANCY. Cad. Saúde Pública, Rio de Janeiro 2016;32 (5): e00066016, http://dx.doi.org/10.1590/0102-311X00066016. Last accessed 10 April 2017.

15. Karla Z. 2016. The Zika Virus Disproportionately Affects the Poor and This is Why Mosquitos thrive in just the kind of environment that's home to the region's poor.2016. https://www.buzzfeed.com/karlazabludovsky/the-zika-virus-disproportionately-affectsthe-poor-and this?utm_term=.asGAmMvAM\#.ngVQbq4Qq. Last accessed 10 April 2017.

16. Alicia EY. N.d. Health, Human Rights, and the Zika Virus, to fight Zika we must fight poverty and powerlessness and ensure that women enjoy their rights. https://fxb.harvard.edu/4941-2/. Last accessed 14April 2017.

17. Sarah B. Zika emergency pushes women to challenge Brazil's abortion law. 19 July 2016. The Guardian.

18. Martha K. Why Are Some Countries Advising Against Pregnancy as the Zika Virus Spreads? RH Reality Check. 1 February 2017. http://rhrealitycheck.org/article/2016/02/01/countries-advising-pregnancy-zika-virusspreads/. Last accessed 19 April 2017.

19. Office of the High Commissioner (OHCHR), United Nations. Upholding women's human rights essential to Zika response Zeid. 2017.

http://www.ohchr.org/EN/NewsEvents/Pages/DisplayNews.aspx?NewsID=17014. Last accessed 19 April 2017.

20. The Lancet Global Health. The Right(s) approach to Zika. 2016; 4: e427.

21. Luna F. Thematic Section: Zika and Pregnancy. Comment on the Paper Pitanguy. Cad. Saúde Pública.2016; 32(5).

22. Karla Z. The Zika Virus Disproportionately Affects the Poor and This Is Why Mosquitos thrive in just the kind of environment that's home to the region's poor.2016. https://www.buzzfeed.com/karlazabludovsky/the-zika-virus-disproportionately-affectsthe-poor-and this?utm_term=.asGAmMvAM\#.ngVQbq4Qq. Last accessed 10 April 2017.

23. Peggy M. Zika to hit poor women hardest. UCLA African Studies Centre. 2016. http://www.international.ucla.edu/africa/article/164174. Last accessed 12 April 2017.

24. Marianna L. The Outbreak of the Zika Virus and Reproductive Rights in Latin America. Feb 24, 2016. http://www.e-ir.info/2016/02/24/the-outbreak-of-the-zika-virus-andreproductive-rights-in-latin-america/. Last accessed 11 April 2017.

25. Peggy M. Zika to hit poor women hardest. UCLA African Studies Centre. 2016. http://www.international.ucla.edu/africa/article/164174. Last accessed 12 April 2017.

26. Debora D. Zika virus, women, and ethics. Developing World Bioethics 2016; 16 (2): 62 63.

27. UNFPA. Poverty, Inequality at the heart of the Zika Outbreak. 21 July 2016. http://www.unfpa.org/news/poverty-inequality-heart-zika-outbreak. Last accessed 14 April 2017.

28. World Health Organization. Zika Causality Statement, Emergencies. 2016. http://www.who.int/emergencies/zika-virus/causality/en/. Last accessed on 18 April 2017.

29. Carla S. Zika virus: ethics preparedness for old and new challenges. The Lancet Global Health. 4; e686.

30. Luna F. Thematic Section: Zika and Pregnancy. Comment on the Paper Pitanguy. Cad. Saúde Pública.2016; 32(5).

31. Jennifer PR. Health and Social Justice. Oxford; 2010.

32. Ibid, 81. 